\title{
Ageing of a giant: a stochastic population forecast for China, 2006-2060
}

\author{
Qiang Li · Mieke Reuser · Cornelia Kraus • \\ Juha Alho
}

Published online: 17 February 2009

(C) The Author(s) 2009. This article is published with open access at Springerlink.com

\begin{abstract}
This paper presents a stochastic population forecast for China with a special emphasis on population ageing. The so-called scaled model for error was used to quantify the uncertainty attached to the population predictions. Data scarcity was a major problem in the specification of the expected error of the population forecast. Therefore, the error structures estimated for European countries were used with some modifications, taking into account the large size and heterogeneity of the Chinese population. The stochastic forecast confirms the expectation of extremely rapid population ageing during the first half of the twenty-first century in China. The old age dependency ratio (OADR) will certainly increase. Simply maintaining the current demographic rates (no international migration) would drive the OADR to 0.42 in 2060, four times the current level. Including expected declines in mortality and net outmigration in the projection would increase the median OADR in 2060 to 0.59 , with a $80 \%$ prediction interval of $[0.47,0.75]$. In particular, the oldest-old population will grow much faster than any other age group. This development has major implications for policy-making in China.
\end{abstract}

Keywords Stochastic population forecast - Predictive distribution · Uncertainty · Scaled model for error · China · Population ageing ·

Low fertility $\cdot$ Mortality decline

Q. Li ( $\square) \cdot$ C. Kraus

Max Planck Institute for Demographic Research, 18057 Rostock, Germany

e-mail: li@demogr.mpg.de

M. Reuser

Netherlands Interdisciplinary Demographic Institute, The Hague, The Netherlands

J. Alho

University of Joensuu, Joensuu, Finland 


\section{Introduction}

The world as a whole and the low-fertility countries in particular face the challenge of a high and accelerating pace of population ageing over the coming decades (Lutz et al. 2008). China, with more than one-fifth of the world's inhabitants, represents a significant factor in the development of the world's population. The population in China is currently ageing at a rapid rate. In 1982, the proportion of the elderly (65 and older) was $4.91 \%$ of the total population, and this share increased to $5.57 \%$ in 1990 and $6.81 \%$ in 2000 . In China it may take only about 20 years for the elderly population to increase from $5 \%$ to $7 \%$, while in many developed countries it usually takes about 50-80 years to develop the same level of population ageing ( $\mathrm{Li} 2005$ ). Hence, population ageing is likely to be one of the great challenges China will face in the near future.

As in most countries, the phenomenon of population ageing in China results from the combined forces of mortality improvement and declining fertility, the latter process being especially pronounced owing to Chinese birth control policies; in February 2006, the Chinese government announced the continuation of these policies. Starting with the restrictive one-child policy in 1980, policies have shifted to one that advocates one child per couple, while modifications to this rule can be made by provinces; for example if the first child is a girl, the couple is allowed to have a second child in rural places; see Gu et al. (2007) for a comprehensive review on China's current fertility and population control policy. These policies, prescribing a below-replacement level of fertility by law, have a large effect on recent and future fertility, leading to an acceleration of population ageing. Average family size has been reduced substantially, impeding family support such as instrumental and financial help as well as caregiving and emotional support, which still play a major role in taking care of the elderly in China (Zimmer and Kwong 2003).

Mortality in China has declined steeply over the past 50 years, especially in the early years of the People's Republic of China (Banister and Hill 2004; Riley 2004). Life expectancy increased from 48 years in 1950-1954 to over 71 years by 2000 (Banister and Hill 2004). Much of the mortality decline can be attributed to the decline in infant and childhood mortality rates achieved by an overall increase in the standard of living and the educational level of the Chinese population (Banister and Hill 2004; Riley 2004). With further improvement of socio-economic development, this mortality decline is likely to continue in the near future.

The Chinese social security system for the elderly is currently being transformed from a solely government-financed to a government-subsidized system. There are limited numbers of older people who receive a pension (Zhang and Xiao 1999). For example, in 1987, 63.7\% of the elderly living in urban areas received pensions, $56.6 \%$ in small towns and $4.7 \%$ in the countryside (Zhang and Xiao 1999). The coverage of medical care cost is about $50 \%$ for employees in the cities and less than $10 \%$ for rural inhabitants (Woo et al. 2002). Most of the older people in China are poor and cannot support themselves. Furthermore, with family size declining, the younger generation will not be able to offer the traditional family care, even if they are willing to do so ( $\mathrm{Li} 2005)$. Recently, the Chinese government has made an effort to reform the social pension system and the medical system with the aim of 
preventing an expected shortfall in retirement payments, and of providing universal basic health care at a reasonable price. Therefore, projecting the Chinese population into the near future is of high importance for providing the relevant demographic background for appropriate socio-economic policy decisions.

To inform policy debates about the likely effect of different intervention strategies, it is necessary to predict not only the level of population ageing, but also the relative effects of the three main population processes on population ageing. Fertility will probably continue to decline or at least keep the current low level. Longevity will almost certainly increase through the improvement in living conditions and the re-establishment of the social security and health care systems. The observed population ageing is mainly the combined effect of these two processes. Recent research shows that international migration plays an increasingly important role for population ageing in several European countries (Alho et al. 2006); in contrast to Western Europe, China is traditionally a labour outmigration country, and consequently the loss of young labour may speed up population ageing.

Forecasting the Chinese population is a challenging task. First, China has been experiencing major demographic changes in the recent past. The implementation of birth control policies starting in 1970, especially the introduction of the one-child policy in 1980, has resulted in a rapid fertility decline. The high rate of economic growth since the Reform and Open-up policy in 1978 has improved public health and living conditions, whereas the collapse of the healthcare system has negatively affected the population's health status, and both have affected mortality. In the face of these dramatic changes in vital rates, deterministic methods are less suitable to capture the uncertainty, while stochastic forecasts have been more successful (Lee and Tuljapurkar 1994). Secondly, data available for forecasting are very scarce and data quality is rather low. Census data for forecasting mortality are available for only four time points. Somewhat more data on fertility are available, but again data quality is poor. For example, fertility rates have been underestimated in several surveys and even in census data (e.g. Guo 2004; Retherford et al. 2005). Moreover, estimates for the total fertility rate (TFR) based on different data sources are not consistent with each other (e.g. Guo 2004). Li et al. (2004) have shown that, given limited data, stochastic forecasts perform better than deterministic ones which have no probabilistic interpretation.

To date, most population forecasts for China have used deterministic projections, which assess the range of possible outcomes by high and low scenarios. Deterministic models have some drawbacks, however. It is not clear how to interpret a population variable's high-low range unless a corresponding probability for the range is provided (Lee and Tuljapurkar 1994). In addition, alternative scenarios based on judgment have tended to underpredict mortality declines and gains in life expectancy when compared with the subsequent outcomes (Keilman 1997, 2001; Lee and Miller 2001). These errors have led to underprediction of the elderly population, and particularly the oldest-old (Li et al. 2004), which could impede population ageing research. Stochastic approaches to forecasting cope with these problems by assuming a probability distribution for the projected parameters. Several methods for probabilistic population projections have been proposed (e.g. Alho and Spencer 2005; Lee and Tuljapurkar 1994). 
To our knowledge, so far only two stochastic forecasts for China have been published: one is a mortality forecast by Li et al. (2004); the other, by Lutz and his colleagues $(2007,2008)$, is a population forecast based on expert opinion: experts are asked to define a probabilistic range for fertility and mortality. Though Lutz et al. $(2007,2008)$ described the population ageing process they did not examine the effect of the different demographic processes on population ageing. In particular, net outmigration was ignored in their forecast. In this study an alternative probabilistic projection approach, the 'scaled model for error' is used to forecast population ageing in China and to assess the contribution of the different demographic processes. The scaled model for error has been developed by Alho and Spencer (2005) and extensively applied to the projection of European populations and the world population (e.g. Alho and Nikander 2004; Alho et al. 2006; Borgy and Alho 2007).

In addition to the uncertainty in future vital rates, forecasting the Chinese population has to take into account the uncertainty of jump-off conditions. Fertility data from different sources are not consistent with each other. Moreover, as a result of sex-selection practices and underreporting of girls since 1980s, millions of girls have been missing and the sex ratio at young ages is extremely high. For example, according to the 2000 Census data, sex ratio at birth was 1.17 . Errors associated with this phenomenon should be included in the uncertainty specification of the forecast. Lutz et al. (2007) considered the uncertainty in current fertility level, sex ratio at birth and the size of youngest age group ( $0-4$ years). Alternatively, in addition to the errors in the current fertility, this forecast includes the uncertainty of the jump-off population after adjusting it for underreporting girls at younger ages (0-20 years).

Focusing on population ageing, the main objectives of this stochastic forecast were to provide probabilistic predictions of total population size; to predict the level and rate of the population ageing process using various indicators of age structure; and to quantify the contributions of expected trends in future fertility, mortality and net outmigration to population ageing. The paper is organized as follows: the following section introduces the data sources and forecasting methods and assumptions for population processes. Stochastic forecasting results are provided in the third section. The final section concludes the study by summarizing the main forecasting results on population ageing and briefly discusses their policy implications.

\section{Methods and materials}

\section{Forecasting method}

The stochastic population forecast in this study employs cohort-component bookkeeping under a linear (Leslie) growth model, with probabilistically varying values for age-specific fertility, age-sex-specific mortality, and net migration flows by sex and age. In addition, given the availability and quality of data in China, the error in the jump-off conditions is also taken into account.

Alho and Spencer (2005) discuss three different methods to determine the predictive distribution for the vital rates: (1) extrapolation of time-series data, 
(2) expert opinion and (3) assessment of accuracy of past forecasts. The choice of the method or combination of methods to use depends mainly on the data situation for the population of interest. The first method requires long and accurate data series from the past. However, the data available for China are too scarce to estimate country-specific levels of uncertainty based on the 'naïve' or baseline forecasts which estimate the forecast error as the median level of uncertainty in the past (Alho and Spencer 2005). Relying on only expert opinion in the forecast can be problematic (Lee 1998); therefore it is often jointly used with other methods. The last method requires extrapolating errors made in past forecasts, which again are not available for China. For countries with insufficient data, Lee (1998) suggested borrowing variance and covariance estimates from carefully selected forecasts for other countries. For this forecast, point estimates for fertility, mortality, and migration were based on the scarce information available and expert opinion (see 'Assumptions for population processes'). The forecasting error structure was borrowed from estimates by Alho and Spencer (2005) who applied the scaled model for error to several European countries.

The scaled model for error is a time-series extrapolation method (Alho and Spencer 2005). It assumes that the errors in demographic rates increase with the time forecast and that the variances of the demographic processes are independent of each other. The scales on the error term are always positive. If an appropriate scale is chosen, a random walk with a drift has been shown to replicate future errors well (Alho and Spencer 1997). The error increments for fertility are assumed to be uncorrelated, that is, following a random walk; for mortality the autocorrelation of errors is presumed to be 0.05 , that is, specifying a random walk with a drift. The uncertainty of migration is expressed in absolute numbers and is similarly modelled by a random walk with a drift with an autocorrelation of 0.3. In addition, the autoregressive (AR(1)-process) correlation of errors across age is assumed to be 0.95 for fertility and mortality, and those across sex are 0.85 for mortality and 0.9 for net migration. ${ }^{1}$

A general empirical finding is that forecasts for large countries have tended to be more accurate than those for smaller countries (Alho and Spencer 2005). Intuitively, the better accuracy appears to be due to the fact that large countries often consist of somewhat independent subpopulations. Thus, the aggregate behaves in a more stable manner than the parts. Indeed, past forecasts for China have shown less bias than those for European countries (Bongaarts and Bulatao 2000). Accordingly, with regard to China's huge population, some downward adjustments of the European scale values were made. Borgy and Alho (2007) used a similar approach to forecast the population for regions lacking demographic data of sufficient quality. In this study, the three scales of fertility, mortality and international migration were multiplied by three different constants, whereas in the Borgy and Alho (2007) study all uncertainty parameters were multiplied by one constant only; more details on uncertainty assumptions are below.

The forecast was made using the programs BEGIN (Yanulevskaya and Alho 2005) and Program for Error Propagation (PEP, Alho and Mustonen 2003), which are based on the scaled model for error. BEGIN creates the forecasting error

\footnotetext{
1 Those error parameters were estimated using European data detailed below.
} 
Table 1 Sources of the data used in the forecast

\begin{tabular}{|c|c|}
\hline Forecast parameters & Data sources \\
\hline Jump-off population (2005) & $\begin{array}{l}\text { United Nations (2007) and adjustment using the short } \\
\text { forecasting as well as for the underreporting of girls }\end{array}$ \\
\hline \multicolumn{2}{|l|}{ Fertility } \\
\hline $\begin{array}{l}\text { Jump-off values for age-specific } \\
\text { fertility rates and TFR }\end{array}$ & The short forecast \\
\hline \multirow[t]{3}{*}{ Annual TFR, 1950-2000 } & Fertility surveys conducted by SFPC \\
\hline & Yearly data from NBS \\
\hline & 2000 Census \\
\hline \multicolumn{2}{|l|}{ Mortality } \\
\hline $\begin{array}{l}\text { Jump-off values for age-specific } \\
\text { mortality rates }\end{array}$ & The short forecast \\
\hline \multirow[t]{2}{*}{ Rate of initial declines } & Cancer Epidemiology Survey (1973-1975) \\
\hline & 1982,1990 and 2000 censuses \\
\hline Rate of ultimate declines & Current European rates (from BEGIN program) \\
\hline \multicolumn{2}{|l|}{ International migration } \\
\hline Net outmigration per year & United Nations (2007) \\
\hline Others & Yearly data from NBS (2002) (for the short forecast) \\
\hline
\end{tabular}

parameters and produces output data files that serve as input in a subsequent PEP run. The cohort component model was run 3,000 times in PEP to determine the probability distribution of future population size and structure. Forecasting results are reported as median with the accompanying $80 \%$ prediction interval, because in most cases $80 \%$ intervals give a better impression of forecast uncertainty than the more common 95\% intervals, which reflect extremes (Alders et al. 2007). The sources of data used in this projection are detailed in Table 1.

Assumptions for population processes

\section{Jump-off population}

China recently released results of the 2005 National 1\% Population Sample Survey (NBS 2007). The 2005 survey was conducted on both a de facto and a de jure basis. ${ }^{2}$ The outcome statistics were estimated on only a de jure basis. According to this report, the total Chinese population in 2005 was estimated at 1,306 million, including an adjustment for the estimated undercount of $1.72 \%$. Because of a lack of critical assessment of the accuracy of these results, however, they were not used to estimate the initial population for this forecast. Instead, the jump-off population was

\footnotetext{
2 The information on the de facto population was mainly used to check the level of migration (floating population) internally. The records for persons who incidentally appeared in households, for example, were deleted and related variables were deleted while the outcome statistics were calculated. We do appreciate the anonymous reviewer for this clarification.
} 
derived by estimating the population in China for 1 July 2005 based on the UN 2006 revision of world population prospects database (UN 2007). This source reported a total population of about 1,313 million at that time for China.

It was necessary to adjust the age-sex-distribution of the jump-off population before forecasting. First, the UN database provides information on the population only by 5-year age groups. Thus, based on the population census data in 2000 as well as available fertility, mortality and net migration data in China, a short stochastic population forecast from 2000 to 2005 was conducted to obtain the age structure within 5 -year age groups ${ }^{3}$ (see Table 1). This age structure was then used to break five-year age groups into single-year age groups.

Secondly, the sex ratios reported in the UN database at younger ages (020 years) are very high and probably biased. For example, the sex ratio at $0-4$ years is 1.16 and continues to be high until age 20, when it is about 1.10. China's distorted sex ratio at younger ages, which is due to a phenomenon often called the 'missing girls', has been the subject of much research lately (Cai and Lavely 2003; Banister 2004; Yuan and Tu 2005). It is now clear that the abnormally high sex ratio is approximately true, not merely an artefact of faulty data. Two factors contribute to the phenomenon: seemingly 'missing girls' which are simply not reported by the parents; and girls truly missing because of sex-selective mechanisms before and after birth. Underreporting accounts for about one-third and sex selection for about two-thirds of the 'missing girls' (Cai and Lavely 2003). The adjustment of the female population and the biased sex ratio at younger ages considered only the underreported girls because they are actually present and play a role in the Chinese population development. The adjustment method proposed by Cai and Lavely (2003) was used in this study. First, the expected sex ratio at each age from 0 to 20 was derived by assuming a sex ratio at birth of 1.06 and subjecting the assumed cohorts by sex to Model West Level 21 mortality, a gender-neutral schedule of mortality (Cai and Lavely 2003). The expected number of females at each age in 2005 was then obtained by dividing the number of males in the above jump-off population by the expected sex ratios, assuming that the male population is fully reported. The difference between the expected number of females and the counted number of females is the number of 'missing girls'. One-third of them, presumably due to underreporting, were added to the reported number of females and the resulting number of females was the adjusted younger females, which was then used to estimate the adjusted sex ratios at younger ages (see Table 2). ${ }^{4}$ This procedure resulted in a jump-off population of 1,318 million at the middle of 2005 by adding an estimated 5.11 million underreported girls.

\footnotetext{
${ }^{3}$ The short forecast applied the method described in section "Methods and materials" so that it is the same one as that used in this forecast. The jump-off population used in the short forecast is based on the adjustment by Wang (2004).

${ }^{4}$ Cai and Lavely's (2003) estimate of the share of seemingly missing girls among the 'missing girls' was based on the comparison of cohorts enumerated as small children in the 1990 census with the same cohorts enumerated 10 years later in the 2000 census. It can be perfectly applied to the modification of sex ratios in 1990. The true adjustment proportion for the sex ratios in 2005 is almost certainly different, but in the absence of other information, extending their conclusions is better than no adjustment at all. Additionally, the assumption of uncertainty in the jump-off population in this study could have specified the errors resulting from such extension.
} 


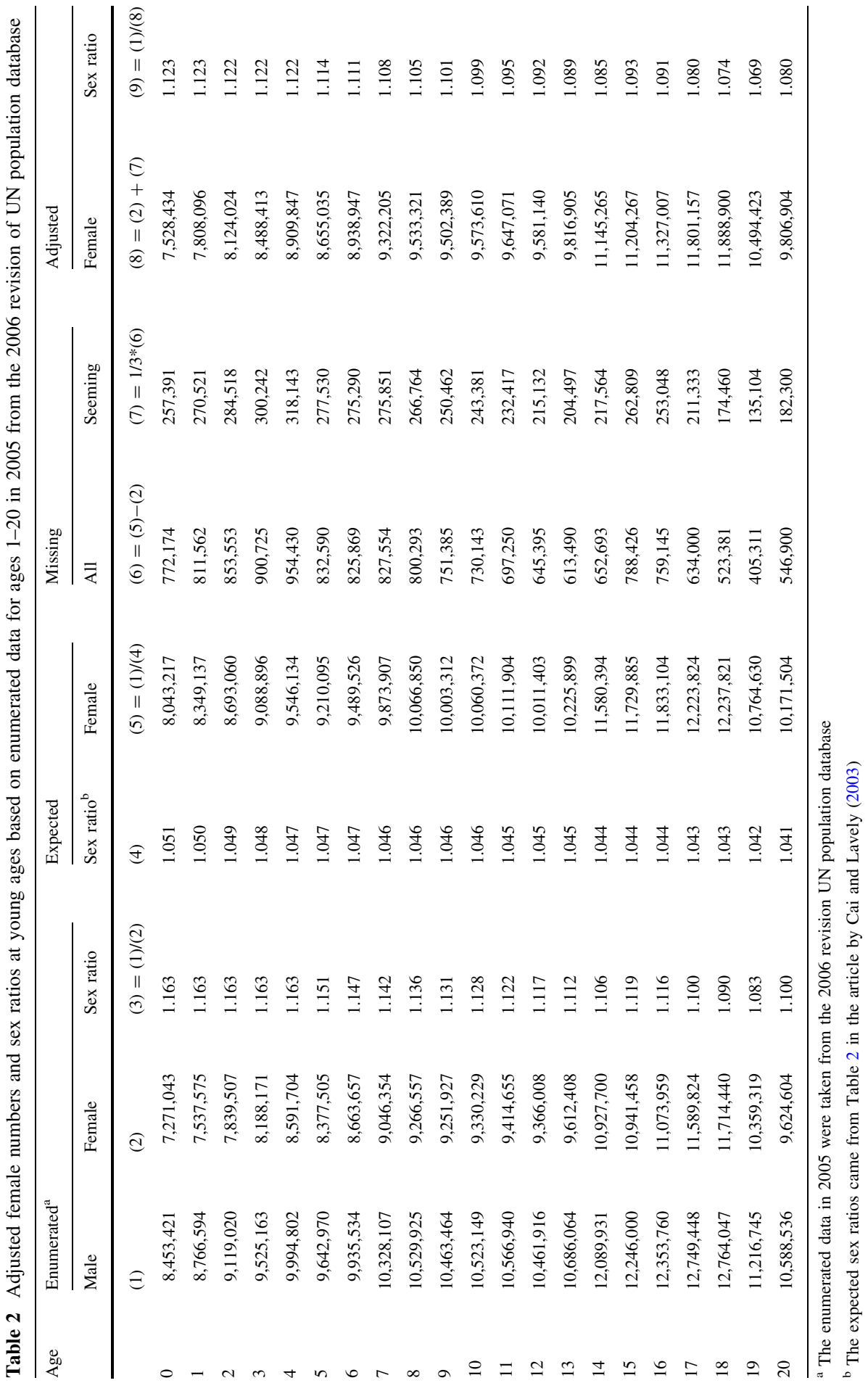


Given the quality of the jump-off population data, additional errors were considered in this forecast. Alho and Spencer $(1985,2005)$ suggested a method to specify uncertainty about the jump-off population, which was adopted in this study. It assumes that the jump-off population follows a normal distribution $N\left(u, \sigma^{2}\right)$; in the case of China with $u=1,318$ million, and $\sigma \approx(1318-1313) / 2=2.5$ million, that is, $0.2 \%$ of population size. This uncertainty results from the underreporting of girls and hence it was specified only to the female jump-off population. In the current version of PEP this kind of uncertainty can be included by adding it to the scales for net migration in the first year.

\section{Fertility}

According to the 2005 National 1\% Population Sample Survey, the TFR in 2005 was 1.33 (NBS 2007). In contrast, the UN (2007) reports a TFR of 1.73 for 2005, which is even higher than the adjusted estimates of 1.59 in 2000, given by Retherford et al. (2005) as well as the estimate of 1.62 for 2000 reported by Zeng (2006). The true value of TFR in 2005 is likely to be lower than the UN value, and, considering the declining trend of fertility, also lower than the estimated values in 2000. Because of these widely differing estimates, this study did not base the TFR assumption on a single source. Instead, TFR data from various sources were taken into account.

The estimation of jump-off fertility was based on past fertility trends between 1950 and 2000 as well as the birth control policies which have played a decisive role in fertility decline and population control in China. Before 1970, TFR fluctuated strongly. The dramatic decline at the end of the 1950s and the beginning of the 1960s was due to the Great Leap Forward beginning in 1957, and subsequently the catastrophic famine of 1959-1962. After that, the TFR increased to a higher level than before the Great Leap Forward and the famine (Fig. 1: left panel). In the past three decades, the fertility trend in China has been dominated by the impact of the 'delayed childbirth (wan), longer birth intervals (xi), and fewer births (shao)' policy of the 1970s, the famous one-child policy introduced in 1980, and the current policy of allowing provinces to modify fertility policies on the basis of the one-child rule according to their own situations (from 1984 onwards). As a result of these policies, fertility declined dramatically from 5.79 to 2.75 in the 1970 s, fluctuated between a maximum value of 2.86 and a minimum of 2.19 during the 1980s, and then fell substantially in the 1990s. Despite differences in TFR estimated from different data sources, the declining trend in fertility during the 1990s is evident (Guo 2004; Zhang 2004; Retherford et al. 2005; Cai 2008).

Regression analysis of the (log-transformed) TFR between 1980 and 2000 from various sources suggested a decline of -0.048 per year. There is no evidence that the fertility decline stopped after 2000. Extrapolating this trend, starting at 1.59 and 1.62 in 2000 yielded an estimated TFR of 1.24 and 1.27 respectively for 2005, even lower than the value of 1.33 from the $20051 \%$ national survey. According to current birth control policies, the target TFR is 1.47 (Guo 2004; Gu et al. 2007). ${ }^{5}$ Guo's (2004) simulation suggested that this target would be reached in 2005. For this

\footnotetext{
5 For estimates of the target TFR see Gu et al. (2007).
} 

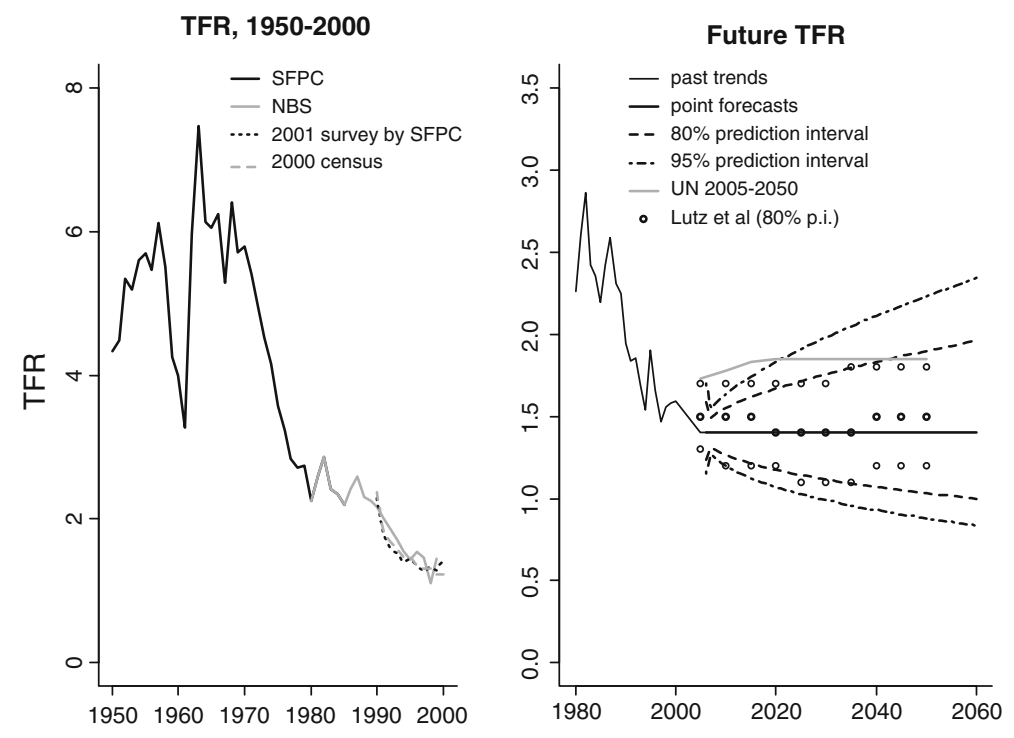

Fig. 1 Total fertility rates in China in 1950-2000, and estimated developments of total fertility rate as well as prediction interval bounds in 2006-2060

forecast the simple mean of all estimates noted above, that is, a value of 1.4, was used as the jump-off TFR. This is lower than the UN's value and the target TFR but higher than the predictions based on the past fertility trend and the estimate from the $20051 \%$ national survey. Obviously, a high level of uncertainty is attached to this value. Thus, it was necessary to include this error at the jump-off time: see the assumption for uncertainty of fertility below. The age-specific fertility rates (ASFR) were obtained from the short stochastic forecast mentioned above (see section "Jump-off population"). The lowest age for which fertility rates are available is 15 years and the highest age is 49 years.

The forecast of TFR was assumed to follow an uncertain path whose expected value is close to 1.4 in the future, that is, until 2060. This assumption is based on the following considerations. There are factors supporting higher levels of TFR, such as a reaction to restrictive policies, but there are also factors that may lead to a further lowering of TFR. Young generations have accepted and internalized the policy into their culture in many places, especially in big cities such as Shanghai, Beijing, Dalian and Shenyang (Nie and Wyman 2005). Particularly, young Chinese women today are more likely to consider childbearing not as a necessity, but as a choice. This may also be due to the rising competition in the labour market as well as the costs of having more than one child. Previous studies have reported a declining trend in the Chinese fertility ideal, from 3 in the 1970s to 1.66 in 2002 (Parish and Whyte 1978; Wang 1996; Chen and Zhang 2003). The fact that we do not have any empirical basis for assuming that TFR will increase rather than decrease or vice versa, is precisely the basis for formulating the forecast in stochastic terms.

Given the limited data available for China, this study borrowed the basic error structure provided by programs BEGIN and PEP to specify the uncertainty for 
fertility assumptions. The default values in BEGIN and PEP were estimated by Alho and Spencer (2005) using six European countries, Denmark, Finland, Iceland, the Netherlands, Norway and Sweden, over the time span starting between 1751 and 1900 , and ending in 2000 . This period includes much turbulence in fertility patterns in the countries studied, such as the 'baby boom' and the rapid fertility declines at the end of the baby boom. Thus, the error structures derived can also serve as a plausible starting point for other countries and areas, such as China. It seems reasonable to assume that uncertainty patterns in China's fertility resemble the European error structures to some extent.

The default values of the fertility scales in BEGIN and PEP, however, were slightly modified downwards, taking into account the large size of the Chinese population compared to the European countries on which the default values are based. The modification was mainly built on the following empirical evidence. Bongaarts and Bulatao (2000) estimated the relative error for the total population of China in 2050 at the lead time of 50 years, using composite bootstrap procedures. On the basis of the European data, Alho and Spencer (2005) showed that after a lead time of about 50 years the levels of forecast error are similar for fertility and mortality; thus, they were constrained to be equal at the end of the forecasting period. In this study, the scales for fertility, mortality and net migration were adjusted until the relative error for the total population in 2050 matched the estimate by Bongaarts and Bulatao (2000). This process resulted in a relative error for fertility of 0.34 in 2060. To account for the uncertainty in the jump-off TFR the scale for fertility in the first year was modified upwards, yielding a $95 \%$ uncertainty range of 1.1-1.8 covering those TFR estimates in 2005 as mentioned above.

In the right panel of Fig. 1 the predictive distribution of TFR is compared to the point forecast of TFR underlying the median scenario of the UN projection, as well as the distribution of TFR assumed by Lutz and his colleagues $(2007,2008)$. The UN forecast is much higher; it assumes the TFR to converge toward a level of 1.85 in 2020 and is held constant at that level for the rest of the projection period (until 2050). It should be noted that the current fertility assumptions differ considerably from those of the UN; however, assumptions used in this study seem plausible. These assumptions lead to $80 \%$ prediction intervals of $[1.09,1.79]$ in 2035 and $[1.00,1.96]$ in 2060 , and $95 \%$ prediction intervals of $[0.96,2.05]$ and $[0.84,2.34]$, respectively. The $80 \%$ prediction interval in this study covers the UN median forecast from 2043, and the $95 \%$ prediction interval covers that from 2020 onwards. Though the point forecast is around 1.4, the fitted model provides essential information about the variance of the stochastic disturbance term. It is evident that the current point assumption is similar to that made by Lutz et al. (2007, 2008), but the resulting $80 \%$ prediction intervals are somewhat wider than those described by Lutz et al. As Lee (1998) pointed out, forecasts based on the 'random scenario' which has been used by Lutz et al. $(2007,2008)$ typically produce a narrower prediction interval than the fully probabilistic approach which was used by this study.

In addition, assumptions for two additional variables, the mean age of childbearing and the sex ratio at birth are required for the forecast. During the 1990 s, the mean age of childbearing, remained stable although the mean age of childbearing by parity had increased (Guo 2004). This was due to the decreasing 
share of women having more than one child, which reduced the effect of the increase of mean age of childbearing by parity. In line with the assumptions about the TFR, it was thus assumed that the expected value of the mean age of childbearing without consideration of parity would remain stable at the current level, that is, 26 years, until 2060. The sex ratio at birth in China has begun to increase above the average (1.06) since the 1980s and has kept rising steeply, reaching 1.16 in 2005. A high incidence of prenatal sex determination and sexselective abortion as well as underreporting are the main causes of the high sex ratio (Cai and Lavely 2003; Banister 2004; Yuan and Tu 2005). The sex ratio at birth declined to 1.12 after adjusting the female population at age 0 for underreporting. Here, the point forecast of the sex ratio at birth is expected to remain constant at 1.12 , since there is currently no evidence for an increasing or decreasing trend in this variable in China.

\section{Mortality}

Age-specific mortality data with the assessment of accuracy for China are only available for the years 1973-1975, 1981, 1990 and 2000. Data for the years 1981, 1990 and 2000 come from the censuses of 1982, 1990 and 2000. The 1973-1975 data stem from the nationwide mortality survey, the 'Cancer Epidemiology Survey' that attempted to record all deaths in nearly all of China's counties and city districts for the 3-year period 1973-1975. This survey provides age-sex-cause-specific mortality rates for the period 1973-1975, which in China represented the time when both rural and urban populations were covered by basic but efficient health-care systems (Banister and Hill 2004; Li et al. 2004). By 1981, the rural health-care system had collapsed, and the city health-care system became inadequate owing to the Reform and Open Up policy launched in 1978.

Mortality rates for the ages $0-100+$ at jump-off time were obtained from the short stochastic forecast (see section Jump-off population). The mortality rates in 2000 used as the starting values in the short forecast were given for single ageclasses, but only up to age-class 90+. The Kannisto model (Thatcher et al. 1998; Zeng and Vaupel 2003) was used to extrapolate death rates up to age $100+{ }^{6}$

Owing to data limitations, mortality assumptions in the forecast were not only based on the observation of past trends in China, but also borrowed from other countries. The age-sex-specific rates of initial decline and ultimate decline in mortality are needed for the forecast. The former was estimated using the available Chinese data, whereas the latter was borrowed from the European countries.

As mentioned earlier, since its establishment, the People's Republic of China has experienced a rapid decline in mortality. In the past three decades, for both sexes, an improvement in mortality at most ages has been observed, except for ages 20-23

\footnotetext{
${ }^{6}$ Three models were examined to describe the hazard function for China: (1) Gompertz, (2) logistic and (3) Kannisto. The latter two were considered because existing evidence suggests that at older ages the increase in mortality decelerates (Thatcher et al. 1998). Models were fitted using maximum likelihood estimation; model selection was based on Akaike's Information Criterion (AIC) as described by Burnham and Anderson (2002). For each year-sex combination, the Kannisto model was strongly supported by the data.
} 

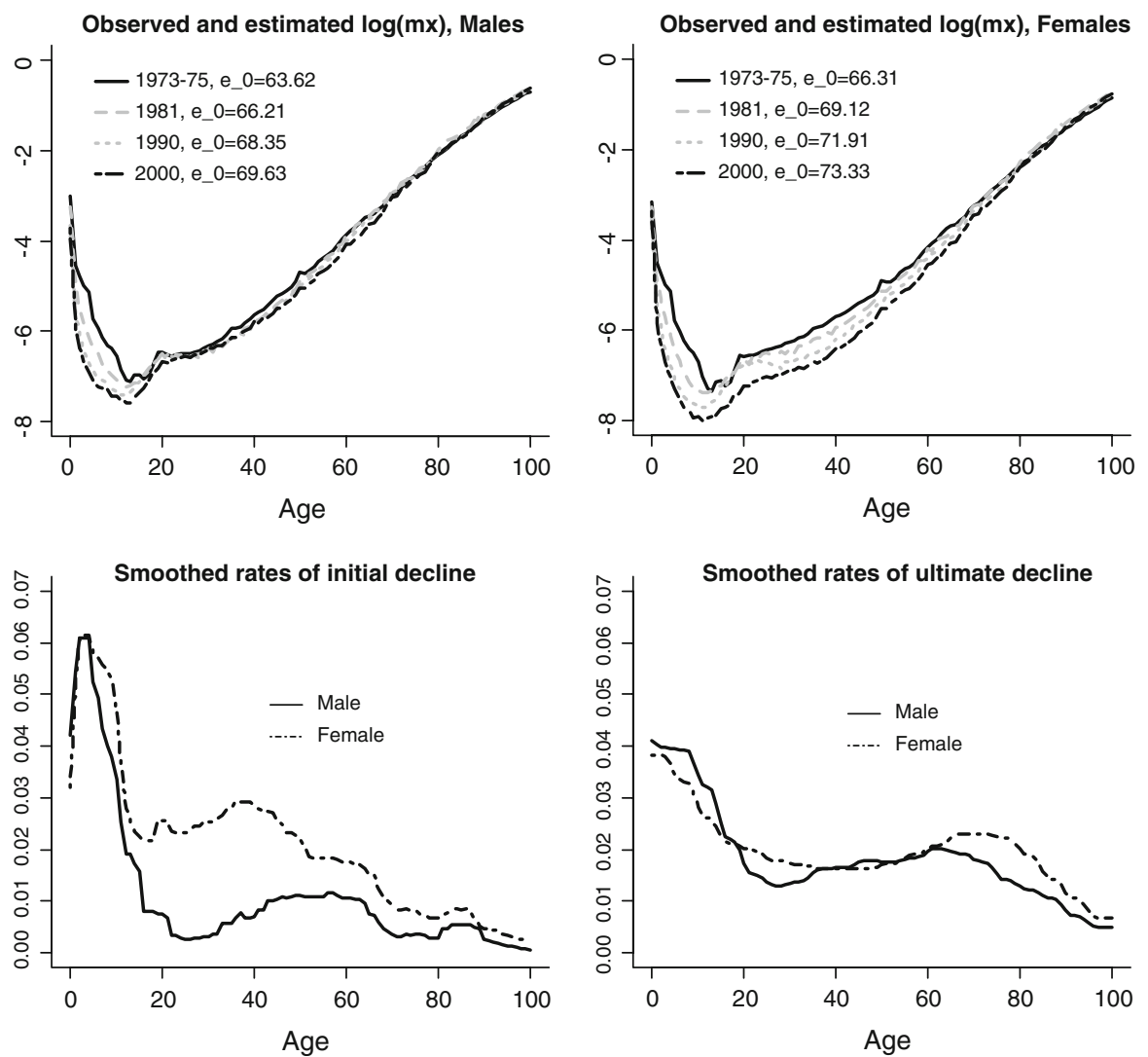

Fig. 2 Observed $\log \left(m_{\mathrm{x}}\right)$ at ages 0-89 and extrapolated $\log \left(m_{\mathrm{x}}\right)$ at ages 90-100+ for males and females, based on Kannisto model fitted to available data; and smoothed rates of decline in age-specific mortality used in the forecast

between 1973-1975 and 1981 (Fig. 2: upper panels). The decline in mortality for males has been more modest than for females, especially in adulthood. One possible explanation is that the improvement in mortality for men has been slowed down by sex-biased occupational and lifestyle factors, such as smoking and alcohol consumption, while women have benefited from a steep decline in fertility, concentration of childbearing at the healthiest ages, longer spacing between births, and the use of modern methods of birth control (Banister and Hill 2004).

It is believed that mortality will continue to decline in the coming years in China for the following two reasons. First, there is room for decline. The estimates of life expectancy were 74.5 years for females and 70.4 years for males in 2005, far below current estimates in the United Kingdom: 2005, 81.1 years for females and 77.1 for males (Eurostat 2008); and Japan: 2006, 85.8 years for females and 79.0 for males (Human Mortality Database 2007). Secondly, there is no indication that the record life expectancy will slow or stagnate in the near future (Oeppen and Vaupel 2002; Bongaarts 2006). Therefore, the changes from 1973-1975 to 2000 are used to 
calculate the rates of initial decline for age-specific mortality (Fig. 2: smoothed rates of initial decline). For forecasting purposes, the rates of initial decline were smoothed, using the 'Running Median Smooth' procedure, and they were restricted to be positive. Mortality has continued to decline fastest at the youngest ages. In the working ages, the mortality decline for females exceeded the decline for males. At old ages, mortality decline was small compared to other age groups, and the sex difference was rather small. Rate of initial decline also indicates that the increase in life expectancy at birth in China during the past three decades was mainly due to the decline in infant, child and adult mortality rather than the decrease in mortality among older people.

As known from empirical evidence, when mortality at younger ages reaches a very low level, further decline becomes much more difficult to achieve. Then, improvement against mortality at older ages is likely to become the dominant force in the increase of life expectancy (Olshansky and Ault 1986). This is currently the case in many European countries such as Germany, Sweden and Finland. Here, it is assumed that the pattern of mortality decline in China in 2060 will closely resemble the pattern shown by European countries in the recent past (Fig. 2: smoothed rates of ultimate decline). This seems plausible because of epidemiological transitions changing the age distribution of deaths (Horiuchi 1997). That is, the rates of decline at younger ages, especially for children and younger women, will decrease and the rates of decline at older ages will increase.

Because the estimated initial rates of mortality decline for adult males are very low, there is much scope for improvement in the future. Adult females' rates of mortality decline have already reached a relatively high level; therefore, the potential for a further decline is decreased. Additionally, rates of mortality decline may decrease because underemployment, which is likely to affect women more strongly than men, may lower relative female social status in the near future. As a result, the sex differences in mortality decline will become smaller at younger ages. At older ages, both males and females are expected to experience higher rates of mortality decline, because new cohorts of the elderly may be healthier than older ones owing to the improvement in living standards and medical progress, but biological sex differences may result in somewhat higher rates of decline for females than for males. Figure 2 (lower right panel) illustrates the smoothed rates of decline for agespecific mortality (using Running Median Smooth) in current European countries, which have been used as the rates of ultimate decline in this forecast.

As for fertility, owing to the lack of long time-series data on age-specific mortality, the error terms estimated by Alho and Spencer (2005) for nine European countries (Austria, Denmark, France, Italy, the Netherlands, Norway, Sweden, Switzerland, and the United Kingdom) were borrowed. Those data end in 2000 and start at various times, the earliest being the United Kingdom in 1841. This was also a period of high volatility of mortality. For China the scale is again adjusted; see the adjustment of the scale for fertility. The relative error in 2060 was calculated at 0.35 . The resulting $80 \%$ and $95 \%$ predictive intervals for life expectancy are plotted in Fig. 3.

According to the forecast distribution, life expectancy at birth for both sexes will increase linearly at a rate of about 2 years per decade. In 2060 females are expected to have a life expectancy of 86.3 years, and males of 80.8 years. The $80 \%$ 

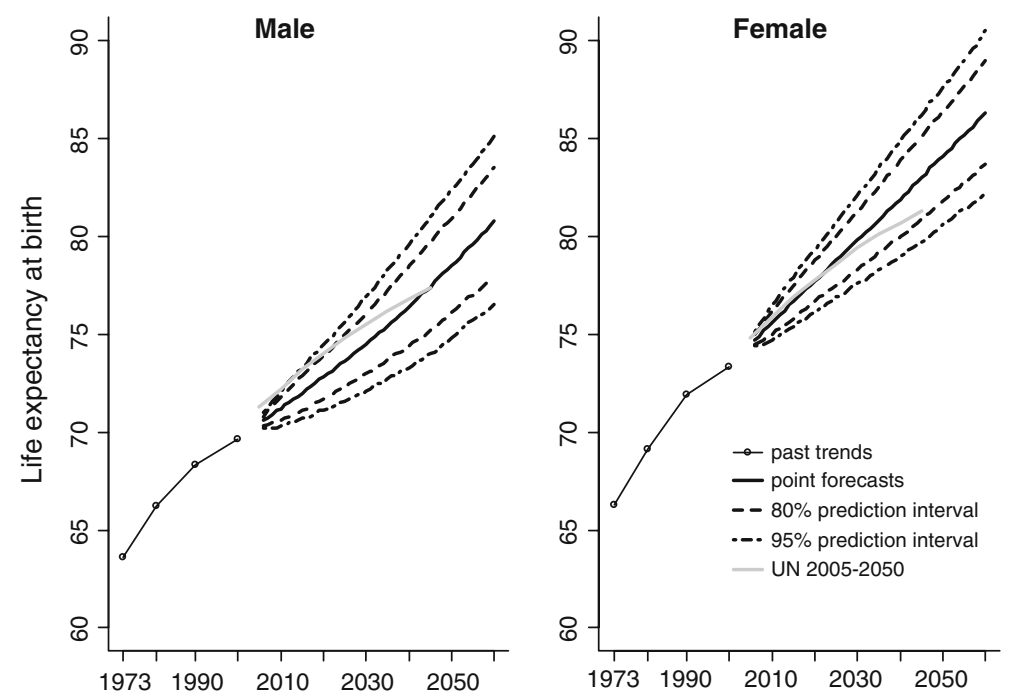

Fig. 3 Estimated life expectancy at birth and prediction interval bounds for males and females

prediction interval for males will be [77.9, 83.5] in 2060, covering a range of 5.6 years $(6.9 \%$ of the median estimate); for females it will be [83.7, 89.0] in 2060, covering 5.3 years $(6.1 \%$ of the median estimate). The $95 \%$ prediction interval at 2060 covers more than 6 years for both sexes.

Figure 3 also compares the forecast of life expectancy to the scenario projection of the UN, which is assumed to be the same for High-Low scenarios (UN 2007). The UN forecasts have traditionally been rather conservative in predicting progress against mortality and have generally underestimated future life expectancy (Keilman 1998; Bongaarts and Bulatao 2000). The forecast of life expectancy in this study seems plausible considering the reinstatement of social security and improvement of the health-care system at the national level, which have already been pronounced as one of the most important tasks by the Chinese government for the set goal of 'Building a Harmonious Society' until 2020.

\section{International migration}

Based on the 1990 census and the $19951 \%$ sample survey, emigration from China in 1995 was about 236,800 (Liang 2001). In 2000, the net migration rate for China was -0.3 migrants per thousand population: this amounted to a loss of approximately 381,000 people. ${ }^{7}$ This means that the net migration as a percentage of the total inhabitants was only $0.03 \%$. The UN forecast predicts that net annual outmigration will decrease from 350,000 to 320,000 in $2050 .^{8}$ This forecast was used as point estimate in this projection; from 2050 to 2060 a constant net outmigration of 320,000 was assumed.

\footnotetext{
${ }^{7}$ See www.nationsencyclopedia.com/Asia-and-Oceania/China-migration.html.

${ }^{8}$ UN World Population Prospects: The 2006 Revision.
} 
Fig. 4 Forecast net cumulative migrations in millions, China 2006-2060

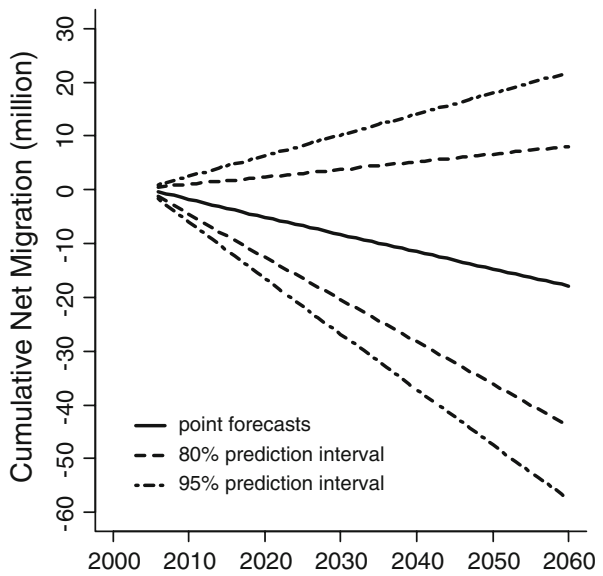

In contrast to fertility and mortality, the uncertainty of international migration is represented in absolute numbers. Its autocorrelation across years was assumed to be constant. Analogous to fertility and mortality, the error terms for migration were borrowed from Europe, in this case 18 European countries (Alho and Nikander 2004). Again, on the basis of empirical evidence it was assumed that China with its huge population and hence large heterogeneity should be well buffered against large shifts in migration (Alho and Spencer 2005). Therefore it seemed appropriate that the scale values should be set relatively low. The resulting assumption of net migration with its associated uncertainty is shown in Fig. 4. Negative values of net migration indicate a net outmigration, that is more people are leaving the country than entering it. In 2060 the $80 \%$ uncertainty interval ranges from -43.9 to +8.1 million and the $95 \%$ bounds are at -57.6 and +21.8 million.

Analysis of forecasting results

\section{Indicators of population change}

Certain demographic indicators are especially suitable to describe changes in population size and structure. Period life expectancy gives the average lifespan of an individual if the current mortality conditions were to persist through life. The changes in the structure of the population over time can be visualized by population pyramids and the following measures of population structure: proportion of elderly, ageing index, old age dependency ratio, oldest-old age dependency ratio (population 80+/population 15-64), and median age.

The division between male and female population is given by the sex ratio, defined as the male population divided by the female population.

\section{Contribution of demographic processes to population ageing}

To assess the relative contribution of the different demographic processes to population ageing, the following stepwise strategy was adopted: (1) the fertility 
point forecast of a constant low TFR level and the corresponding error was used, while mortality rates were kept constant at the jump-off level and net migration was assumed to remain at zero. (2) Fertility was specified as in Step 1, and, the assumed mortality decline and its associated error were also included; net migration was still kept constant at zero. (3) The 'actual forecast' fertility and mortality were specified as in Step 2 and combined with the assumed net outmigration and its corresponding error, which is described in more detail in the section on "Assumptions for population processes". The OADR was chosen as the indicator of population ageing for showing the results from these three steps. The three point forecasts of OADR were compared to quantify the net effect of constant low fertility, mortality decline and net outmigration on population ageing. Forecasting results of the first two steps are used only for the comparison of OADR. The forecasting results from the third step represent the probabilistic projection of population size and population ageing.

\section{Results}

Total population size up to year 2060

The median of the forecast distribution projects China's total population to increase from the jump-off level of 1,318 million at the middle of 2005 to its maximum level at 1,372 million people in 2024 , and thereafter predicts its decline to 1,114 million people in 2060 (Fig. 5: total population. For comparison, only the 95\% predictive interval was plotted). Note that owing to the large number of simulation runs $(3,000)$, the mean and median are equal. The long increase despite the well-belowreplacement TFR is due to a strong population momentum.

There is considerable uncertainty attached to the median estimates, including temporal as well as magnitude effects. The upper $80 \%$ prediction interval suggests an increase up to 1,440 million people in 2031, whereas the lower one estimates a peak population of only 1,335 million in 2017. Additionally, the upper $95 \%$ prediction interval gives an increase up to 1,548 million until the end of the forecast, while the lower one predicts a maximum population of only 1,324 million in 2014. In 2060 the $80 \%$ prediction interval covers a range of 947-1,364 million (37\% of the median estimate), while the $95 \%$ prediction range covers a range of $877-1,548$ million ( $60 \%$ of the median estimate).

Compared to the Chinese population forecast of the United Nations World Population Prospects in 2006, the predictions lie a bit lower than the High-Low scenario. The difference is mainly due to the fact that the UN assumed a higher TFR, 1.35-2.35, by mid-century, while it is expected to be within the range of 0.842.34 (95\% interval) in this forecast. Recall that under the UN high scenario the TFR is 2.35 for the whole projection period, while the upper bound on TFR in this forecast merely says that in every single year there is a $2.5 \%$ chance that fertility may be this high, and similarly for the low scenario. Furthermore, the UN used rather conservative mortality assumptions underlying their population projection. 

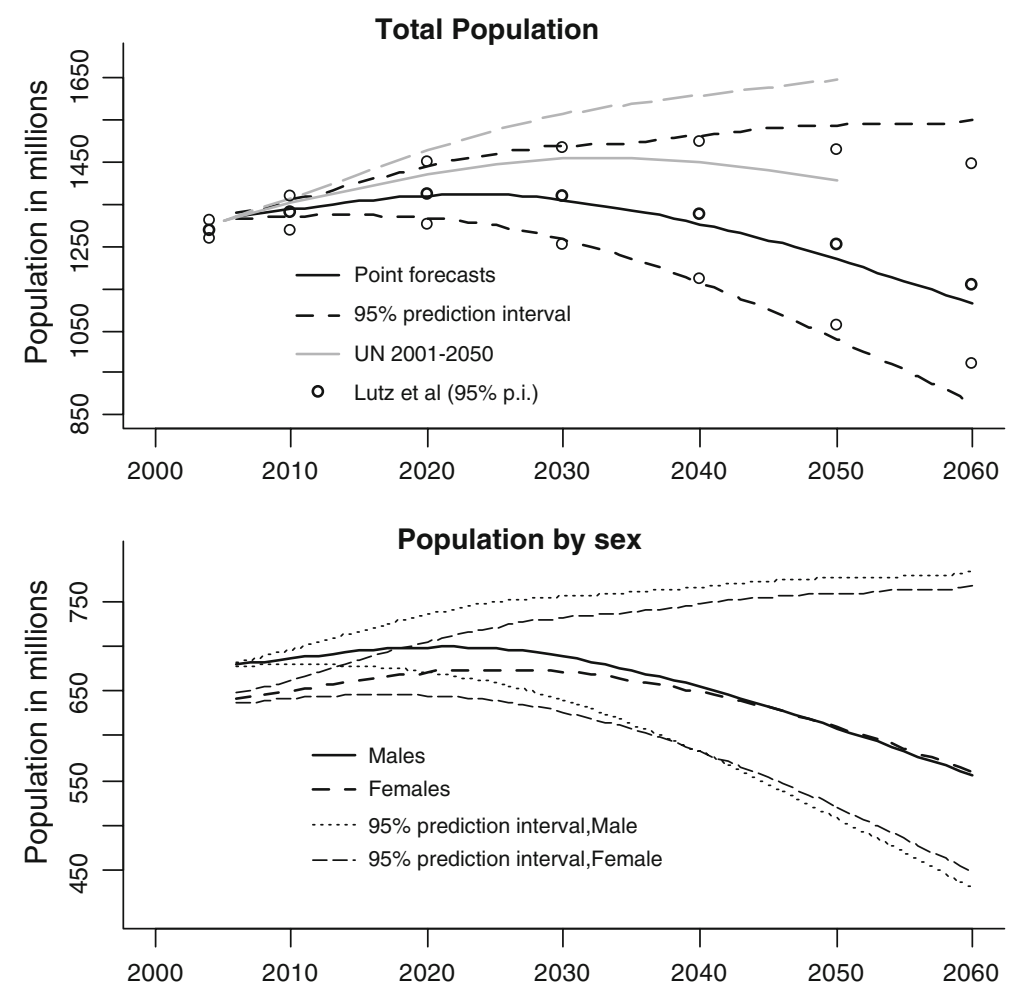

Fig. 5 Projected developments of China's total population in millions and 95\% prediction intervals compared to UN high, medium and low variants as well as Lutz et al.'s forecasting results and male and female population in millions, 2006-2060

The median forecasts of the total population by Lutz et al. (2007, 2008) are similar to those of this forecast. According to Lutz et al. a peak of 1,375 million will be reached between 2020 and 2030 and then the population is predicted to decline slowly. In 2060 , the median is down to 1,157 million. This similarity may result from similar assumptions on fertility and mortality: Lutz et al. assume that the future TFR covers $80 \%$ in the range between 1.3 and 1.7 in $2005,1.0-2.0$ by 2030 , with linear interpolation between 2000 and 2030, as well as 1.2-1.8 in 2050, and life expectancy is on average assumed to increase by 2 years per decade. Part of the difference of 43 million in the projected population for 2060 may be due to their assumption of no international migration. Their $95 \%$ prediction interval is also very close to that of this study until 2040. Thereafter, the $95 \%$ range of this forecast becomes somewhat wider than that of Lutz et al. (2007).

The projected population development differs slightly for males and females. Whereas the male population will peak at 699 million in year 2021, the female population will reach its maximum size in 2026 at 671 million. Figure 5 (lower panel) shows that the gap between the number of males and females closes in 2045 after which the female population exceeds the male one slightly, presumably because females have lower mortality at working ages and old ages. 


\section{Age-sex structures}

The population pyramids in Fig. 6 illustrate the evolving age-sex structure over the projection interval, visualizing the rapid rate of population ageing. From the predominance of the childhood and the working-age class in current China, it is predicted to shift to an age-structure characteristic of ageing populations in Europe.

The population snapshots shown in Fig. 6 depict how the uncertainty spreads from the youngest age classes along the age axis over the forecast period. For the old age classes, the slower growth of uncertainty reflects the lower initial level of uncertainty for mortality. This can be understood easily since the younger age classes are born during the forecast years, while the older ones were already born before 2005; as a result, the younger age classes have a larger uncertainty attached than the older ones. After 55 years, the predictive distribution of the Chinese population composition ranges from a column-like to a rather regressive age pyramid, with most of the uncertainty attached to the base of the pyramid.
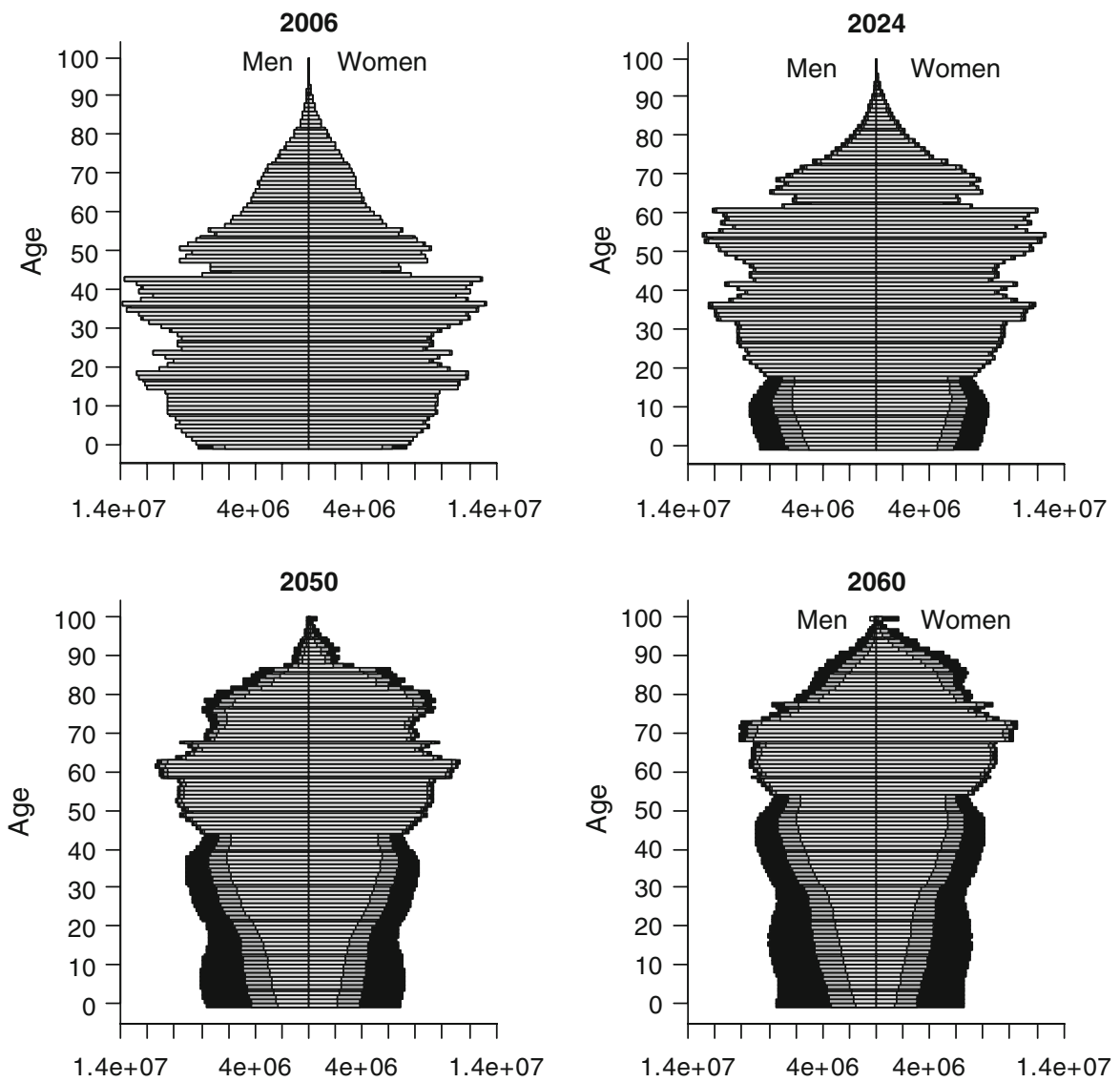

Fig. 6 Population pyramids for 2006, 2024, 2050 and 2060 and 80\% uncertainty intervals. Inner pyramid shows lower boundary (10\%) and black the upper boundary (90\%) of the $80 \%$ uncertainty interval 
The rapid pace of population ageing in China can also be seen in other indicators of population age-structure (Table 3). Life expectancy will increase consistently for both sexes (see Fig. 3). Owing to steady improvement in mortality rates, the proportion of elderly (65+) is expected to increase more than fourfold during the next 55 years, from about $7.75 \%$ [7.73, 7.77] in 2006 to $33.5 \%$ [27.0, 39.9] in 2060: about one-third of the population. Combined with the permanently belowreplacement level of fertility, the decline in mortality will raise the ageing index even faster: a ninefold increase from 37 [37, 37] in 2006 to 332 [173, 633] in 2060 is predicted. The median age of the total population increases from age $34[34,34]$ in 2006 to $51[46,56]$ in 2060.

Table 4 shows the temporal development of sex-specific indicators of the population age structure. The sex gap in life expectancy is predicted to increase moderately from 4.1 years in 2006 to 5.1 years in 2060. Because of the lower agespecific mortality rates in females, by 2060 the age-sex-structure is expected to be highly asymmetrical with a sex ratio of $0.8[0.73,0.87]$ among the elderly and 0.56 $[0.43,0.69]$ among the oldest-old. As a further consequence, the sex differential in ageing will increase rapidly. While the median age of males and females differs by only one year in 2006, by 2060, a gap of 4 years is expected to have opened. Also, in absolute numbers the female older and oldest-old population increases much faster than that of the males, with the differentials being largest for the $80+$ population.

\section{Old age dependency ratio}

There remains no uncertainty to the fact that the OADR in China will rise steeply over the next 55 years (Fig. 7: upper left panel): the median of the predictive distribution suggests a more than fivefold increase from 0.11 to 0.59 , from a level typical for Asian countries to one comparable to that expected in more developed countries such as Australia (Wilson and Bell 2004). Even the lower bound of the 95\% predictive intervals would represent a quadrupling of the current level, let alone the more than eightfold increase indicated by the upper bound. It is unlikely for China to escape population ageing. With the highly biased sex-ratio at birth (1.12) and the lower mortality of females in working ages, the absolute numbers of population size for the ages $65+$ and $80+$ increase much faster for females than for males.

The OADR produced by this stochastic forecast gives meaningful, quantitative upper and lower bounds to the degree of ageing. As discussed in detail by Alho et al. (2008), measures such as age-dependency ratios cannot be satisfactorily produced using High-Low forecast variants. For example, a dependency ratio calculated from a high scenario forecast is not necessarily either smaller or larger than a dependency ratio calculated from a low scenario forecast. If high fertility is combined with low mortality to derive the high scenario, a moderate OADR is generated, and similarly for the low scenario. The choice of these bundles minimizes the high-low range of the OADR. To illustrate this, the predictive distribution of OADR in this forecast is compared with the OADR forecast of the UN (Fig. 7, upper left panel). The central tendency of this forecast is higher than that of UN, owing to its lower fertility and more rapid mortality decline. The $95 \%$ predictive interval in this forecast is double that of the High-Low variant of UN. 


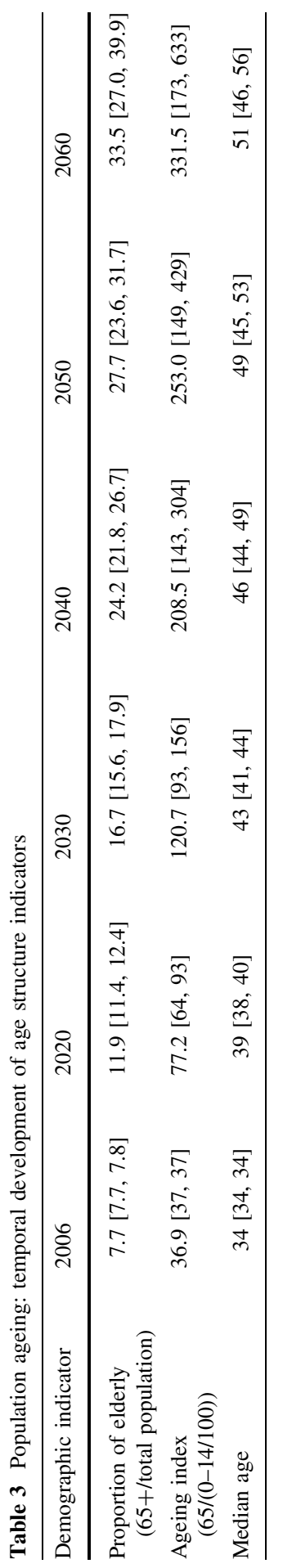




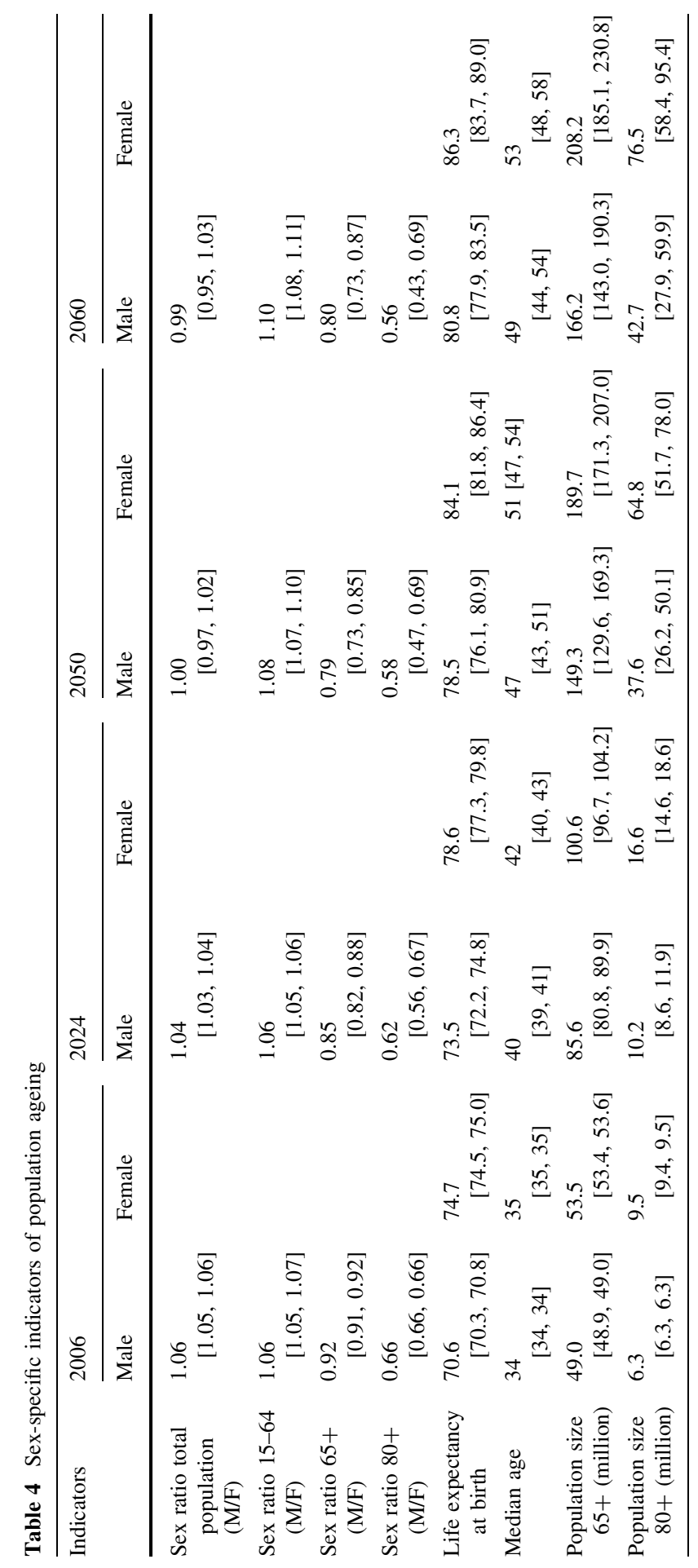



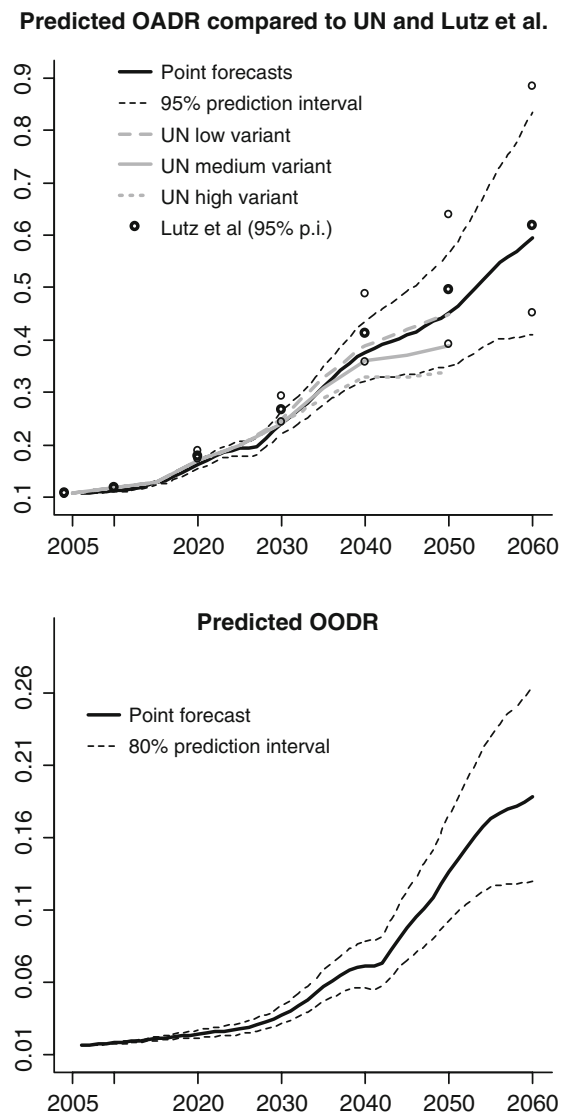

Point OADR under different assumptions
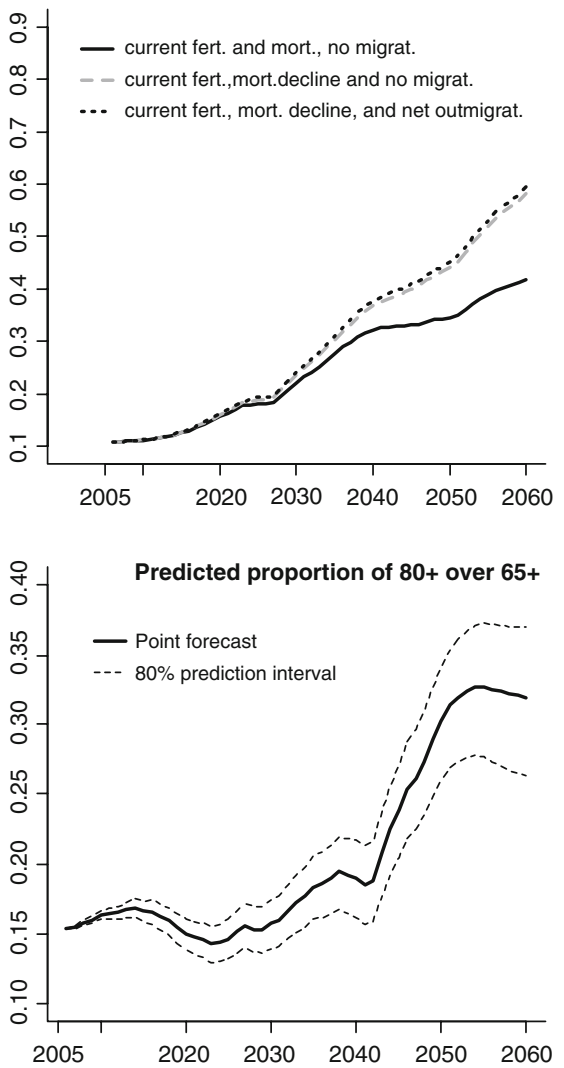

Fig. 7 a Predicted OADR and 95\% prediction intervals, compared to UN forecasts low, medium and high variants and Lutz et al., b predicted point OADR under different fertility, mortality and net international migration assumptions, $\mathbf{c}$ total predicted OODR, and $\mathbf{d}$ predicted proportion of $80+$ population over $65+$ population, China 2006-2060

The comparatively narrow interval given by the UN forecast results from the particular pattern of covariation built into their fixed trajectory of vital rates, that is, their 'high' and 'low' scenarios combine normal mortality and migration with lower and higher fertility in the whole prediction period. It also sets perfect correlations between errors for fertility, mortality and migration over time without further addressing how likely such combinations are to occur (Booth 2004; Lee 2004). The merit of an OADR derived in this way is often doubted (Lee 2004; Alho et al. 2008). Based on this forecast, there is a considerable probability that population ageing may be much more severe than that considered by the UN.

To evaluate how robust the OADR results are to the specific assumptions made in the forecast, they are compared with the OADR forecasts of Lutz et al. (2007). The increasing trend of the OADR predicted by this forecast is similar to that described in Lutz et al. The median OADR estimated by Lutz et al. is higher than that of this forecast, which is somewhat surprising. Given the similar mortality decline assumed 
in the two projections, 2 years per decade, their assumption of higher fertility levels and no young labour outmigration should yield a lower OADR than this forecast. The explanation may lie in the different sex ratio dynamics. First, though the sex ratio at birth, 1.18, in the jump-off population of the Lutz et al. forecast is higher than the one underlying this projection, 1.12, the sex ratio in the former is lower from age 20 onwards than in this forecast, owing to a steeper decline in sex ratio over age. Secondly, in their projection the sex ratio at birth declines from 1.18 in 2000 to 1.05 in 2030, while in this forecast the sex ratio at birth remains constant at 1.12 until the lead time. The first difference results in a higher number of elderly females because working-age females have lower mortality than their male counterparts in their forecast. The second difference will produce a smaller working age population since working-age males suffer increased mortality. Consequently, their median forecast of OADR is somewhat higher than that of this forecast.

Probabilistic forecasts for 18 European countries predict a total European OADR of 0.57 in 2050 (Alho et al. 2006). However, Alho et al. use a slightly different definition of the OADR for the European forecast: using age group 20-64 instead of 15-64 as denominator. If that definition were applied in this study, the forecast OADR would increase to $0.48[0.42,0.56]$ and be even closer to the OADR of the European countries in 2050.

It is important to note, though, that for the European countries, in the period 2000-2050, the OADR as defined above will double from 0.28 to 0.57. As mentioned before, China will reach a level of 0.48 in 2050, using the Alho et al. (2006) definition, but starts off from a much lower level, around 0.1 in 2000 . Hence the OADR will multiply by 4.8 over the 50 projection years. This means that the pace of ageing is more than twice as fast in China as in Europe.

The oldest-old class will expand even more rapidly than the total old age class $(65+)$ (Fig. 7: lower panels). According to the median of the projection, the oldestold age dependency ratio (OODR) will multiply by more than 11 for both sexes; from 0.017 in 2006 to 0.188 in 2060, and the proportion of the oldest-old among the total old-age group would double, from 0.15 to 0.3 . The upper bound of $80 \%$ interval for the OODR is fifteen times the current one. Figure 7 (lower panels) shows a sharp increase after 2040, which can be explained by the baby-boom cohort born in the 1960s that will reach the oldest-old class in 2040 (see also Fig. 1: left panel). The decrease in the proportion of the oldest-old over the elderly after 2055 probably reflects the impact of the sharp fertility decline in the late 1970s.

What are the contributions of mortality decline and net outmigration to population ageing given the very low fertility in China? The point forecasts of OADR resulting from each step of the strategy described above are shown in Fig. 7 (upper right panel). If there would be no decline in mortality and net outmigration in China over the next 55 years, the OADR would increase from 0.11 in 2006 to 0.42 in 2060, assuming that the current low fertility level of about 1.4 births per woman would be maintained throughout the forecast period. Inclusion of the expected decline in mortality would yield an OADR of 0.58 by $2060,38 \%$ higher than with no decline in mortality and net outmigration. Additional incorporation of net outmigration would increase the OADR to only 0.59 by 2060 , suggesting a negligible affect of the migration process on population ageing. Together, these 
findings indicate that the degree of population ageing will be highly dependent on the future fertility and mortality in China.

\section{Discussion}

This paper reports the results of a stochastic population forecast for China until 2060 with a focus on the process of population ageing, and quantifies the expected uncertainty. Data limitation is a big challenge in projecting the Chinese population. Thus, in this study forecast errors estimated for some European countries with longterm and reliable historical data were borrowed, and some adjustments on scales were made, taking the large size and heterogeneity of the Chinese population into consideration. The overall level of uncertainty has been calibrated to match the empirical error for the total population in 2050 estimated by Bongaarts and Bulatao (2000). The rationale behind this paper is to make use of all available empirical sources to forecast the population stochastically, while acknowledging the uncertainty of the estimates, resulting from the country's lack of data.

In the Chinese application the major merit of stochastic methods is that the forecasts produce logically coherent and interpretable predictive distributions for any measure of ageing that is of interest. The comparison of the projections of the Chinese population reported by the UN and the present probabilistic forecast provides solid support for this advantage. Stochastic methods have been successfully applied in macro-economic studies of ageing in the United States (Auerbach and Lee 2001) and Europe (Alho et al. 2008). In these applications the logical problems of conventional forecasts are compounded, because different aspects of demographic change interact to produce the economic consequences. This study suggests that a similar application would be useful to assess the likely economic correlates of population ageing in China.

The predictions produced by this forecast are similar to that by Lutz et al. (2007), despite some differences in the methodological details. Whereas Lutz et al. used expert opinion to define the probabilistic interval for fertility and mortality assumptions in combination with a random interval scenario to pick the time course of vital rates, this study used a probabilistic approach based on time series analyses. In addition to the uncertainty attached to the future changing vital rates, this forecast specified the uncertainty on the current TFR and jump-off population which was adjusted for the underreporting of girls at younger ages (0-20 years), while Lutz et al. included errors in current TFR, sex ratio at birth and the size of the youngest age group (years 0-4). Taking these differences into account, overall the predictions based on the stochastic projections seem quite robust against minor to moderate differences in the underlying assumptions.

\section{Population ageing is certain in China 2006-2060}

The key result of this study is that while there is considerable uncertainty attached to the predicted development of Chinese population size over the next 55 years, there can hardly be any doubt that the Chinese population is ageing quickly. Even without the 
expected declines in mortality and net outmigration of young labour, the OADR will be four times the current level by 2060 , driven only by the very low TFR. Including declines in mortality and net outmigration in the projection leads to a median OADR of 0.59 which is more than five times the current level; with $95 \%$ probability the OADR will be between 0.41 and 0.83 in 2060. The forecast raises concerns about the possibility of an enormous increase in the cost of public old-age pensions.

Another striking development is that the population of the oldest-old will grow faster than any other age group in China between 2006 and 2060, yielding a very high OODR. Because of the huge population in China, the absolute size of the oldest-old class is very large. Members of this class differ from those of the youngold class: they are much more likely to have extensive co-morbidity, and the decline of their functional ability accelerates with age (Fries et al. 2000; Zeng et al. 2002; Baltes and Smith 2003). Thus, they consume amounts of services, benefits and transfers far out of proportion to their population share (Suzman et al. 1992). Taken together, this indicates the necessity to prepare for providing sufficient care, services, benefits and transfers for this rapidly growing part of the population.

It should be recalled that one of the forecasting assumptions used was that the ultimate rates of decline in mortality will equal those in European countries at present. If China does not achieve the same rates of decline in mortality as Europe, the present results for population size, life expectancy and OADR will be somewhat biased upwards. Still, the rapid population ageing process will not slow down substantially, even if no longevity increase is anticipated.

This forecast points towards severe disadvantages for elderly women in China. Because females have a higher life expectancy than males, the share of older females in the population is larger and increases faster than for males. Moreover, this gap increases over age and the projected time period (see Table 4). Some previous studies have shown that elderly Chinese women are much more likely to be widowed and economically more dependent (Zeng and George 2000). At the same time, the social security for them is much poorer than for their male counterparts (Jia 2006). In short, women's quality of life in old age will be at risk.

\section{Policy implications}

Facing such a dramatically rapid pace of population ageing, what are the measures Chinese decision-makers should consider? Potential counter-strategies should address the causes as well as the symptoms of population ageing, by including adjustments of fertility policies and elderly support systems.

China should smoothly adjust its current birth control policies toward a less restrictive one that allows a larger number of couples to have more than one child. This would certainly be the most effective defence against rapid population ageing and has been proposed by some other studies (e.g. Gu et al. 2007; Zeng 2007; Cai 2008). The current stochastic forecasts confirm the necessity of an adjustment of birth control policies by providing a demographic basis which is logically coherent and interpretable. The future elderly of the forecasting period have already been born, but an increase in fertility would result in a higher percentage of people in the working ages. At the macro level, this would increase the denominator and thus 
reduce the OADR. At the micro level, adjusting fertility policy would also be helpful in reducing adult children's burden in the support of their elderly parents because there will be siblings to share the load. It is important to remember that in China, with its huge population, any change in population policy could result in large absolute changes. Thus, any adjustment should be planned very carefully. How to adjust the fertility policy exactly is beyond the present research. Further forecasting that focuses on policy making could help to evaluate the potential effects of different fertility policies on population ageing.

In today's China, the family support system which has been working for thousands of years still plays the dominant role in supporting the elderly. Old age insurance programs are insufficient, especially in rural areas. China has not yet found a suitable model to build a functioning old age insurance program. Thus, in the next 55 years, besides continuing to encourage family support, China should devote resources to establish age insurance and healthcare programs. Fortunately, the Chinese government has now realized that the lack of a sufficient social security system will impede sustainable development in China, and it has started to reestablish this system and improve the medical system. A latest survey on China's social pensions showed that more than 240 million Chinese have been covered by the social pension system (including 187 million urban workers), and the average monthly pension for retirees from enterprises has doubled (China.org.cn. 2008). At the beginning of 2008, the government announced at a national health conference that it would reform the medical system to reduce the involvement of hospitals in drug sales and spend more government money to set up basic health care services for both rural and urban citizens. Establishing a functioning social security system is one of the most important tasks in the set goal of 'Building a Harmonious Society' by 2020 . As discussed here, the severe disadvantages confronting elderly women require special attention from family, society and government. Old age insurance programs should benefit older women and men equally, and care services should take elderly women's poorer health and economic status into account.

Acknowledgments An early version of this paper was produced as part of Prof. Juha Alho's course 'Population Forecasts' at the European Doctoral School of Demography (EDSD) in 2006. The current version incorporates all new and relevant information regarding the population development in China. The authors would like to thank Jutta Gampe (MPIDR), Joop de Beer (NIDI) and Beata Nowok (NIDI) for constructive comments on an earlier draft. We are also grateful to two anonymous reviewers and the editor of the Journal of Population Research for their helpful comments. For valuable language editing, we would like to thank Susann Backer.

Open Access This article is distributed under the terms of the Creative Commons Attribution Noncommercial License which permits any noncommercial use, distribution, and reproduction in any medium, provided the original author(s) and source are credited.

\section{References}

Alders, M., Keilman, N., \& Cruijsen, H. (2007). Assumptions for long-term stochastic population forecasts in 18 European countries. European Journal of Population, 23(1), 33-69.

Alho, J. M., Alders, H. C., Keilman, N., Nikander, T., \& Pham, D. Q. (2006). New forecast: Population decline postponed in Europe. Statistical Journal of the United Nations ECE, 23, 1-10. 
Alho, J. M., Cruijsen, H., \& Keilman, N. (2008). Empirically based specification of forecast uncertainty. In J. M. Alho, S. E. Hougaard Jensen, \& J. Lassila (Eds.), Uncertain demographics and fiscal sustainability (pp. 34-54). New York: Cambridge University Press.

Alho, J. M., \& Mustonen, M. (2003). Tutorial for PEP-program for stochastic forecasts of population. http://www.joensuu.fi/statistics/pep/peptutorial.pdf\#search=\%22Alho\%20Mustonen\%20PEP\% 22. Accessed 24 Aug 2007.

Alho, J. M., \& Nikander, T. (2004). Uncertain population of Europe-summary results from a stochastic forecast. http://www.stat.fi/tup/euupe/rp_reports_and_pub.html. Accessed 24 Aug 2007.

Alho, J. M., \& Spencer, B. D. (1985). Uncertain population forecasting. Journal of the American Statistical Association, 80, 306-314.

Alho, J., \& Spencer, B. D. (1997). The practical specification of the expected error of population forecasts. Journal of Official Statistics, 13, 203-225.

Alho, J. M., \& Spencer, B. D. (2005). Statistical demography and forecasting. New York: Springer.

Auerbach, A., \& Lee, R. D. (2001). Demographic change and fiscal policy. Cambridge: Cambridge University Press.

Baltes, P. B., \& Smith, J. (2003). New frontiers in the future of aging: From successful aging of the young old to the dilemmas of the fourth age. Gerontology, 49(2), 123-135.

Banister, J. (2004). Shortage of girls in China today. Journal of Population Research, 21(1), 19-45.

Banister, J., \& Hill, K. (2004). Mortality in China 1964-2000. Population Studies, 58(1), 55-75.

Bongaarts, J. (2006). How long will we live? Population and Development Review, 32(4), 605-628.

Bongaarts, J., \& Bulatao, R. A. (Eds.). (2000). Beyond six billion: Forecasting the world's population. Washington, DC: National Academy Press.

Booth, H. (2004). On the importance of being uncertain: Forecasting population futures for Australia. People and Place, 12(2), 1-12.

Borgy, V., \& Alho, J. M. (2007). Macro-economic consequences of demographic uncertainty in world regions. In J. M. Alho, S. E. Hougaard Jensen, \& J. Lassila (Eds.), Uncertain demographics and fiscal sustainability (pp. 195-218). New York: Cambridge University Press.

Burnham, K. B., \& Anderson, D. R. (2002). Model selection and multimodel inference: A practical information-theoretic approach. New York: Springer.

Cai, Y. (2008). An assessment of China's fertility level using the variable-r methods. Demography, 45(2), 271-281.

Cai, Y., \& Lavely, W. (2003). China's missing girls: Numerical estimates and effects on population growth. China Review, 3(2), 13-29.

Chen, S., \& Zhang, S. (2003). Research on contemporary people's preference of marriage and childbearing: 2002 national preference of marriage and childbearing survey. Beijing: China Population Publishing House.

China.org.cn. (2008). 240 million Chinese covered by social pension system. http://www1.china.org. cn/english/GS-e/234474.htm. Accessed 06 Feb 2008.

Eurostat. (2008). Population. http://epp.eurostat.ec.europa.eu/portal/page?_pageid=1996,45323734\&_d $\mathrm{ad}=$ portal\&_schema=PORTAL\&screen=welcomeref $\&$ open=/popula/pop/demo/demo_mor\& language $=$ en \&product=EU_MASTER_population\&root=EU_MASTER_population\&scrollto=0. Accessed 20 Apr 2008.

Fries, B. E., Morris, J. N., Skarupski, K. A., Blaum, C. S., Galecki, A., Bookstein, F., et al. (2000). Accelerated dysfunction among the very oldest-old in nursing homes. Journal of Gerontology Series A: Biological Sciences and Medical Sciences, 55(6), M336-M341.

Gu, B., Wang, F., Guo, Z., \& Zhang, E. (2007). China's local and national fertility policies at the end of the twentieth century. Population and Development Review, 31(1), 129-147.

Guo, Z. (2004). Fertility in China in the 1990s. Population Research, 28(2), 10-19. (in Chinese).

Horiuchi, S. (1997). Epidemiological transitions in developed countries: Past, present and future. Paper presented at Symposium on Health and Mortality, Brussels, 19-22 November.

Human Mortality Database. (2007). University of California, Berkeley (USA), and Max Planck Institute for Demographic Research (Germany). http://www.mortality.org/. Accessed 20 Apr 2008.

Jia, Y. (2006). The Chinese elderly women. http://www.china.org.cn/chinese/zhuanti/fnfzbg/11562 83.htm. Accessed 24 Aug 2007.

Keilman, N. (1997). Ex-post errors in official population forecasts in industrialized countries. Journal of Official Statistics, 13, 245-277.

Keilman, N. (1998). How accurate are the United Nations world population projections? Population and Development Review, 24, 15-41. 
Keilman, N. (2001). Uncertain population forecasts. Nature, 412(6846), 490-491.

Lee, R. D. (1998). Probabilistic approaches to population forecasting. In Lutz, W., Vaupal, J. W., \& Ahlburg, D. A. (Eds.), Frontiers of population forecasting. Supplement to Population and Development Review, 24, 156-190.

Lee, R. D. (2004). Quantifying our ignorance: Stochastic forecasts of population and public budgets. Center for the Economics and Demography of Aging. CEDA Papers 2004-0001CL. http://repositories.cdlib.org/iber/ceda/papers/2004-0001CL.

Lee, R. D., \& Miller, T. (2001). Evaluating the performance of the Lee-Carter approach to modeling and forecasting mortality. Demography, 38(4), 537-549.

Lee, R. D., \& Tuljapurkar, S. (1994). Stochastic population projections for the United States: Beyond high, medium and low. Journal of the American Statistical Association, 89(428), 1175-1189.

Li, Y. (Boni). (2005). The challenges of aging toward Chinese society. Public Administration and Management: An Interactive Journal, 10(3), 25-45.

Li, N., Lee, R. D., \& Tuljapurkar, S. (2004). Using the Lee-Carter method to forecast mortality for populations with limited data. International Statistical Review, 72(1), 19-36.

Liang, Z. (2001). Demography of illicit emigration from China: A sending country's perspective. Sociological Forum, 16(4), 677-701.

Lutz, W., Scherbov, S., Cao, G., Ren, Q., \& Zheng, X. (2007). China's uncertain demographic present and future. Vienna Yearbook of Population Research, 2007, 37-59.

Lutz, W., Sanderson, S., \& Scherbov, S. (2008). The coming acceleration of global population ageing. Nature (letter). doi:10.1038/nature06516. http://www.nature.com/nature/journal/vaop/ncurrent/ extref/nature06516-s1.pdf. Published online 20 January 2008.

National Bureau of Statistics (NBS) of China, Population Census Office under the State Council and Department of Population, Social, Science and Technology Statistics. (2002). Tabulation on the 2000 population census of the People's Republic of China. Beijing: China Statistics Press.

National Bureau of Statistics (NBS) of China, Population Census Office under the State Council and Department of Population, Social, Science and Technology Statistics. (2007). Tabulation of the 2005 National One Percent Population Sample Survey. Beijing: China Statistics Press.

Nie, Y., \& Wyman, R. J. (2005). The one-child policy in Shanghai: Acceptance and internalization. Population and Development Review, 31(2), 313-336.

Oeppen, J., \& Vaupel, J. (2002). Broken limits to life expectancy. Science, 296(5570), 1029-1031.

Olshansky, S. J., \& Ault, A. B. (1986). The fourth stage of the epidemiologic transition: The age of delayed degenerative diseases. Milbank Quarterly, 64(3), 355-391.

Parish, W. L., \& Whyte, M. K. (1978). Village and family in contemporary China. Chicago: University of Chicago Press.

Retherford, R. D., Choe, M. K., Chen, J., Li, X., \& Cui, H. (2005). How far has fertility in China really declined? Population and Development Review, 31(1), 57-84.

Riley, N. E. (2004). China's population: New trends and challenges. Population Bulletin, 59(2), 3-36.

Suzman, R. M., Willis, D., \& Manton, K. (1992). The oldest old. New York: Oxford University Press.

Thatcher, A. R., Kannisto, V., \& Vaupel, J. W. (1998). The force of mortality at ages 80 to 120. Odense: Odense University Press.

United Nations (UN). (2007). World population prospects. The 2006 revision population database. http://esa.un.org/unpp/.

Wang, F. (1996). A decade of the one-child policy: Achievements and implications. In A. Goldstein \& F. Wang (Eds.), China: The many facets of demographic change (pp. 97-120). Boulder: Westview Press.

Wang, G. (2004). On data evaluation and adjustment for age structure of the fifth census of China. Population and Economics, 5, 60-66 (in Chinese).

Wilson, T., \& Bell, M. (2004). Australia's uncertain demographic future. Demographic Research, 11, 195-234. http://www.demographic-research.org/volumes/vol11/8/11-8.pdf. Accessed 24 Aug 2007.

Woo, J., Kwok, T., Sze, F. K. H., \& Yuan, H. J. (2002). Aging in China: Health and social consequences and responses. International Journal of Epidemiology, 31(4), 772-775.

Yanulevskaya, V., \& Alho, J. M. (2005). Tutorial for BEGIN. http://joyx.joensuu.fi/ ek/pep/Begin Tutorial.pdf\#search=\%22Tutorial\%20for\%20BEGIN\%22. Accessed 24 Aug 2007.

Yuan, X., \& Jow-Ching Tu, E. (2005). High sex ratio at birth and female deficit in China. Paper presented at International Conference on Female Deficit in Asia: Trends and Perspectives, Singapore, 5-7 December. http://www.cicred.org/Eng/Seminars/Details/Seminars/FDA/PAPERS/19_YuanXin.pdf. Accessed 24 Aug 2007. 
Zeng, Y. (2006). Population aging, 'Two-Child Plus Spacing' policy, and economic and social development in China. China Internet Information Center. http://ccer.pku.edu.cn/cn/ReadNews. asp?NewsID=6131. Accessed 24 Aug 2007.

Zeng, Y. (2007). Options for fertility policy transition in China. Population and Development Review, $33(2), 215-246$.

Zeng Y., \& George, L. (2000). Family dynamics of 63 million (in 1990) to more than 330 million (in 2050) elders in China. Demographic Research, 2, 1-48.

Zeng, Y., \& Vaupel, J. W. (2003). Oldest-old mortality in China. Demographic Research, 8, 215-244. http://www.demographic-research.org/Volumes/Vol8/7/8-7.pdf. Accessed 24 Aug 2007.

Zeng, Y., Vaupel, J. W., Xiao, Z., Zhang, C., \& Liu, Y. (2002). Sociodemographic and health profiles of the oldest old in China. Population and Development Review, 28(2), 251-273.

Zhang, G. (2004). Very low fertility in China in the 1990s: An illusion of birth underreporting? Paper presented at Annual Meeting of the Population Association of America, Boston, 1-3 April.

Zhang, J., \& Xiao, L. (1999). Discussion on the reform direction of the social security system in China. Social Security System, 2, 48-50.

Zimmer, Z., \& Kwong, J. (2003). Family size and support of older adults in urban and rural China: Current effects and future implications. Demography, 40(1), 23-44. 